\title{
Spekülarit Cevherinin Kalite Özelliklerinin İyileştirilmesi
}

\author{
Hüseyin VAPUR ${ }^{* 1}$, Soner TOP ${ }^{1}$ \\ ${ }^{1}$ Çukurova Üniversitesi, Mühendislik Mimarlık Fakültesi, Maden Mühendisliği Bölümü, Adana
}

Geliş tarihi: 29.01 .2016

Kabul tarihi: 22.03.2016

\section{Özet}

$\mathrm{Bu}$ çalışmada Adana/Feke Bölgesi’nden alınan spekülarit cevheri için fiziksel ayırma yöntemleri endüstride kullanılabilecek özelliklere sahip konsantre elde edilmesi için uygulanmıştır. Kuvars minerali cevherdeki temel safsızlık olarak saptanmıştır. Manyetik zenginleştirme yöntemlerinden kuru manyetik, yaş manyetik ayırma yöntemleri ile gravite ayırma yöntemlerinden sallantılı masa ile ayırma yöntemi uygulanmıştır. Yüksek alan şiddetli yaş manyetik ayırma ile $\% 62,94 \mathrm{Fe}_{2} \mathrm{O}_{3}$ içeren cevherden 6000 Gauss manyetik alan şiddetinde $\% 92,47 \mathrm{Fe}_{2} \mathrm{O}_{3}$ tenörlü konsantre $\% 69,91$ kazanma verimiyle elde edilebilmiştir. Kuru manyetik ayırma işlemi ile $\% 75,62 \mathrm{Fe}_{2} \mathrm{O}_{3}$ içeren konsantre \%89,43 verimle kazanılırken sallantılı masa deneylerinde $\% 71,7 \mathrm{Fe}_{2} \mathrm{O}_{3}$ içerikli konsantre \% 75,54 kazanma verimiyle elde edilmiştir. Sonuçlar, spekülarit cevherinin demir-çelik ve boya endüstrisinde hammadde olarak kullanılabilecek özellikte zenginleştirileceğini göstermiştir.

Anahtar Kelimeler: Spekülarit, Manyetik ayırma, Sallantılı masa, Cevher zenginleştirme

\section{Improving of Quality Properties of the Specularite Ore}

\begin{abstract}
In this research, physical separation methods for a specularite ore taken from Adana/Feke region were applied to obtain a concentrate, which is suitable for industrial usages. Quartz mineral in the specularite ore was detected as basic impurity. Dry/wet magnetic separation techniques from magnetic beneficiation methods and shaking table tests from gravity separation methods were applied. The best concentrate with $92,47 \% \quad \mathrm{Fe}_{2} \mathrm{O}_{3}$ grade and $69,91 \%$ recovery yield could have been obtained from the ore containing $62,94 \% \mathrm{Fe}_{2} \mathrm{O}_{3}$ by high intensity wet magnetic separation method at 6000 Gauss magnetic field strength. Also, the concentrate which has $75,62 \% \mathrm{Fe}_{2} \mathrm{O}_{3}$ grade with $89,43 \%$ yield was enriched by dry magnetic separation while the other concentrate with $71,7 \% \mathrm{Fe}_{2} \mathrm{O}_{3}$ grade and $75,54 \%$ recovery yield was obtained by shaking table tests. The results show that specularite ores can be beneficiated for using in steelmaking and painting industries as a raw material.
\end{abstract}

Keywords: Specularite, Magnetic separation, Shaking table, Ore processing

\footnotetext{
*Yazışmaların yapılacağı yazar: Hüseyin VAPUR, Mühendislik Mimarlık Fakültesi, Maden Mühendisliği Bölümü, Adana.hvapur@cu.edu.tr
} 


\section{GíRiș}

Spekülarit (olijist), demir siyahı renginde kuvvetli metal parlaklığında, porselen üzerinde kırmızı kırmızı kahverengi bir çizgi bırakan gevrek yapılı bir demir mineralidir $\left(\mathrm{Fe}_{2} \mathrm{O}_{3}\right)$. Sertliği 6,5 ve yoğunluğu 5,2-5,3 arasındadır. Hidroklorik asitte $(\mathrm{HCl})$ yavaş yavaş erir, üfleçte erimez bariz romboedrik kristalleri olduğu gibi pullu cinsi demir mikası adını almaktadır. Manyetit, ilmenit ve kromit ile karıştırılabilir [1,2]. Spekülarit, korozyona karşı direnç sağlaması dolayısıyla boya endüstrisi ve demir içeriğinden ötürü demir-çelik tesislerinde kullanılabilir. Demir cevherlerinin yüksek firında indirgenerek pik demir oluşumu için gerekli karbon, firına beslenen kokun yanması sonucu oluşan $\mathrm{CO}$ ve $\mathrm{CO}_{2}$ gazları yardımıyla oluşur. 1, 2 ve 3 numaralı eşitlikler uyarınca gerçekleşen tepkimeler sonucu pik demir elde edilir.

$$
\begin{aligned}
& 3 \mathrm{Fe}_{2} \mathrm{O}_{3(\mathrm{k})}+\mathrm{CO}_{(\mathrm{g})} \rightarrow 2 \mathrm{Fe}_{3} \mathrm{O}_{4(\mathrm{k})}+\mathrm{CO}_{2(\mathrm{~g})}\left(450^{\circ} \mathrm{C}\right) \\
& \mathrm{Fe}_{3} \mathrm{O}_{4(\mathrm{k})}+\mathrm{CO}_{(\mathrm{g})} \rightarrow 3 \mathrm{FeO}_{(\mathrm{k})}+\mathrm{CO}_{2(\mathrm{~g})}\left(850^{\circ} \mathrm{C}\right) \\
& \mathrm{FeO}_{(\mathrm{k})}+\mathrm{CO}_{(\mathrm{g})} \rightarrow \mathrm{Fe}_{(\mathrm{s})}+\mathrm{CO}_{2(\mathrm{~g})}\left(1200^{\circ} \mathrm{C}\right)
\end{aligned}
$$

Demir toplumların ekonomik ve sosyal gelişmelerinde en büyük katkısı olan elementlerden ve endüstrinin temel girdilerinden biridir. 1960-1974 yılları arasında dünya çelik üretimi yıllık $\% 7$ ortalama artış hızı ile çok büyük bir gelişme kaydetmiştir. Batı Avrupa ve Japonya'daki büyük bütünleşmiş demir çelik tesislerinin kuruluşları bu dönemin karakteristik endüstriyel yatırımları olmuşlardır. Türkiye'de demir çelik sektörü, başta yassı ve yapısal çelik ürünlerine yönelik yatırımlar olmak üzere, özellikle 2001 yılından sonra, hızlı bir büyüme ivmesi kazanmıştır. 2006-2012 döneminde, Türkiye'nin ham çelik üretim kapasitesi 28,4 milyon ton artışla, 50 milyon ton seviyesine ulaşmıştır. Söz konusu artış, 66 yılda ulaşılan kapasiteden yüzde 130 daha büyük bir kapasitenin, son 6 yılda devreye alındığını göstermesi bakımından önem taşımaktadır.

Ancak yüksek kaliteli paslanmaz çelik üretiminin ülkemizde olmaması önemli bir dezavantajdır. Türkiye, 2012 yılında gerçekleştirdiği 35,9 milyon tonluk ham çelik üretimi ile 2011 yılına kıyasla, 2 sıra birden yükselerek, y1lı dünyanın en fazla ham çelik üreten 8'inci ülkesi olarak tamamlamıştır. 2012 yılı verilerine göre, Türkiye ham çelik üretimini kriz öncesi olan 2007 yılındaki seviyesinin yüzde 39 oranında üzerine taşımıştır. $\mathrm{Bu}$ yönüyle Türkiye, dünyanın en büyük 10 çelik üreticisi arasında, üretimini kriz öncesi seviyesinin üzerine çıkartan 5 ülke arasında yer almıştır [3-6]. Artan üretimi karşılamak için demir cevherinin ve taş kömürün önemli bir kısmı yurt dışından ithal edilmektedir. Türkiye'de cevher harmanında kullanılmak üzere satın alınan cevherde aranan ortalama kimyasal kompozisyonlar Çizelge 1'de görülmektedir.

Çizelge 1. Demir-çelik tesisleri için ortalama tenör değerleri [5].

\begin{tabular}{|c|c|c|}
\hline İçerik (\%) & $\begin{array}{c}\text { Doğrudan } \\
\text { Şarjlık }\end{array}$ & Sinterlik \\
\hline $\mathrm{Fe}_{2} \mathrm{O}_{3}$ & 91,50 & 88,65 \\
\hline $\mathrm{SiO}_{2}(\max )$ & 5,00 & 5,00 \\
\hline $\mathrm{Al}_{2} \mathrm{O}_{3}(\max )$ & 1,00 & 1,50 \\
\hline $\mathrm{CaO}+\mathrm{MgO}(\max )$ & 1,00 & 1,00 \\
\hline $\mathrm{S}(\max )$ & 0,02 & 0,02 \\
\hline $\mathrm{K}_{2} \mathrm{O}+\mathrm{Na}_{2} \mathrm{O}(\max )$ & 0,10 & 0,10 \\
\hline $\mathrm{As}(\max )$ & 0,01 & 0,01 \\
\hline $\mathrm{Mn}(\max )$ & 1,50 & 5,00 \\
\hline $\mathrm{Cu}(\max )$ & 0,01 & 0,01 \\
\hline $\mathrm{P}(\max )$ & 0,06 & 0,06 \\
\hline $\mathrm{Pb}(\max )$ & 0,01 & 0,01 \\
\hline $\mathrm{Zn}(\max )$ & 0,01 & 0,01 \\
\hline $\mathrm{Cr}(\max )$ & 0,05 & 0,05 \\
\hline $\mathrm{Ni}(\max )$ & 0,01 & 0,01 \\
\hline
\end{tabular}

Halen paslanmaz çelik üretilemese de Türkiye'nin ham çelik üretimine bakıldığında sürekli bir büyüme ve artış göze çarpmaktadır. Elektrik ark firınları ve bazik oksijen firınlarında geri dönüştürülen hurda demir ithalatında birinci sıradaki Türkiye'nin hammaddeden çelik ve kaliteli çelik üretimine hız vermesi gerekmektedir. Ayrıca hurda gemi, askeri teçhizat vb. geri dönüşüm (recovery, recycling or reuse) hammaddeleri zararlı maddeler içerebilmektedir. Özellikle boya sanayi açısından demir oksit pigmentleri doğal ve sentetik olmak üzere başlıca iki gruba ayrılır. Yaygın doğal demir oksit pigmentler Çizelge 2'de gösterilmektedir. Doğal 
demir oksit pigmentleri, dört ana bölümde incelenir. Bunlar, ocher (okr), umber (ombra), sienna (siyena) ve kırmızı demir oksitlerdir. Gruplandırmalarında ise ana kriterler renk değişimleri ve kimyasal içerikleridir. Genellikle okrlar sarıdan kırmızıya değişen tonlarda, siyenalar sarıdan turuncuya değişen tonlarda, ombralar ise koyu kahverengi tonlarında değişim gösterir.

Çizelge 2. Demir oksit pigmentler (*kalsine edildiğinde) [9].

\begin{tabular}{|c|c|c|}
\hline \multicolumn{3}{|c|}{ Yaygın Demir Oksit Pigmentler } \\
\hline Mineral & Kompozisyon & Renk(ler) \\
\hline Hötit & $\alpha \mathrm{FeO} . \mathrm{OH}$ & Sarı, kahverengi \\
\hline Lepidokrozit & $\mathrm{Fe}_{2} \mathrm{O}_{3}$ & $\begin{array}{c}\text { Kırmızı } \\
\text { (pigment olarak) }\end{array}$ \\
\hline Manyetit & $\mathrm{Fe}_{3} \mathrm{O}_{4}$ & Sarı \\
\hline Siderite & $\mathrm{FeCO}_{3}$ & $\begin{array}{c}\text { Kirmah } \\
\text { kahverengi* }\end{array}$ \\
\hline Pirit & $\begin{array}{c}\mathrm{FeS}_{2} \\
\text { lematit, götit, } \\
\text { lepidokrozit } \\
\text { karışımı, } \\
\text { absorbe edilmiş } \\
\text { su ile birlikte }\end{array}$ & Sarı, kahverengi* \\
\hline Spekülarit & $\begin{array}{c}\text { Mikalı demir } \\
\text { oksit, hematitin } \\
\text { mikalı } \\
\text { bir çeşidi }\end{array}$ & $\begin{array}{c}\text { Demir siyahi, } \\
\text { metalik parlaklık }\end{array}$ \\
\hline \multicolumn{2}{|c|}{} \\
\hline
\end{tabular}

Demir oksit pigmentlerinin kalite sınıfları Çizelge 3'te gösterilmiştir. Mikalı demir oksitler spekülar hematit olarak da bilinmektedir. En önemli kaynakları Avusturya, İspanya, Güney Afrika ve Avustralya'dır. Spekülaritin en önemli özelliği termal duyarlılığıdır. Spekülarit minimum $\% 85 \mathrm{Fe}_{2} \mathrm{O}_{3}$ içeriğine sahip olmalı ve içinde çözünebilen tuzlar minimum olmalıdır. Spekülaritin romboedrik kristalleri olduğu gibi, pullu cinsi demir mikası ismini alır. Demir çelik sektörü için ise $\mathrm{SiO}_{2}$ içeriği \%5'ten az olmalıdır. Yüksek silis oranı yüksek firının yapısına uygun değildir. Türkiye'de spekülarit rezervlerinin Adana ve Erzurum bölgelerinde olduğu bilinmektedir [7-9].

Bu çalışmada Adana'nın Feke ilçesine ait spekülarit cevherinin zenginleştirilmesine yönelik sallantılı masa, yaş manyetik ayırma ve kuru manyetik ayırma testleri gerçekleştirilmiştir. Elde edilen konsantrenin demirçelik ve boya sanayi için kullanılabilmesi amaçlanmıştır.

Çizelge 3. Demir oksitlerin boya endüstrisindeki kalite siniflamaları [9].

\begin{tabular}{|c|c|c|c|c|}
\hline \multirow{2}{*}{ Demir Oksit Türü } & \multicolumn{4}{|c|}{$\% \mathrm{Fe}_{2} \mathrm{O}_{3}$} \\
\cline { 2 - 5 } & A & B & C & D \\
\hline Kırmızı & 95 & 70 & 50 & 10 \\
\hline Sarı & 83 & 70 & 50 & 10 \\
\hline Kahverengi & 87 & 70 & 30 & - \\
\hline Siyah & 95 & 70 & - & - \\
\hline Mikalı & 85 & - & - & - \\
\hline
\end{tabular}

\section{2. ÖNCEKİ ÇALISSMALAR}

Uzun zamandır devam eden yüksek tüketim artış1 kolay zenginleştirilebilir demir rezervlerini azaltmıştır. Ayrıca teknolojinin hızlı gelişimi de demir tenörleri oldukça yüksek, zararlı elementleri mümkün olduğu kadar az konsantreler üretmeyi zorlamaktadır. 15000 Gauss'un üzerinde alan şiddetleriyle çalışan manyetik ayırıcıların ekonomik olarak hematit zenginleştirilmesinde kullanıldığı günümüzde alçak ve yüksek alanda manyetik ayırma-ters flotasyon yöntemlerinin konbinasyonlarıyla, zor zenginleştirilebilen demir cevherleri de başarılı olarak zenginleştirilebilmektedir [3, 10]. Ancak yüksek işletme maliyetleri nedeniyle çok ince ögütme gerektiren yöntemlerin endüstriyel ölçekte kullanımı sınırlıdır. Xiuping ve Arkadaşları [11], safsızlık olarak \%13 kalsit, \%10 kuvars ve $\% 8$ klorit içeren spekülarit cevherini zenginleştirmek için ters flotasyon işlemini uygulamışlardır. Kalsit ve kuvars ilk aşamada anyonik kollektör olan sodyum oleat ile yüzdürülürken, kloriti yüzdürmek için katyonik kollektör olan eter amin kullanılmıştır. Sonuçta \%65,28 demir içeren konsantre \% 79,05 verimle kazanılmıştır.

Wang ve diğerleri [12], \%35 demir içeren spekülarit cevherinden yüksek alan şiddetli manyetik ayırma ve ters flotasyon işlemlerinin kombinasyonuyla \%66,62 demir içeren 
konsantreyi \%58,38 verimle kazanmıștır. Wei-guo (2011), ardışık şekilde düşük alan şiddetli manyetik ayırıcı-yüksek alan şiddetli manyetik ayırıcı ve ters flotasyon işlemlerini uygulayarak $\% 64,12$ demir içeren konsantreyi \%70,39 verimle elde edebilmiştir. Besleme malının \%85'inin boyutu $74 \mu \mathrm{m}$ 'nin altı olarak seçilmiştir. Düşük alan şiddetli manyetik ayırıcının manyetik alan şiddeti $167 \mathrm{kA} / \mathrm{m}$ iken yüksek alan şiddetli manyetik ayırıcının manyetik alan şiddeti 0,8 Tesla'dır. Ters flotasyon işleminde kaba flotasyon konsantresi alınmakta iken, artıklara kaçan demir 3 adet süpürme flotasyonunu izleyen temizleme flotasyonu ile kazanılarak verim artışı sağlanmıştır [13]. Literatürde demir cevherinin gang minerallerinden ayrımına yönelik yoğunluk ve manyetik özellik farkı yardımıyla gerçekleştirilen çalışmalar oldukça fazladır [14-17].

\section{MATERYAL VE METOT}

Çukurova Üniversitesi Maden Mühendisliği Bölüm Laboratuvarları'na getirilen örnek spekülarit cevheri numunesinin konileme-dörtleme işlemi ile numune azaltılmasının ardından kırma+ögütme işlemi ile boyutu küçültülmüştür. Boyut küçültme işleminin ardından yapılan elek analizi sonucu malzemenin tane boyut dağılımı Şekil 1'de görülmektedir.

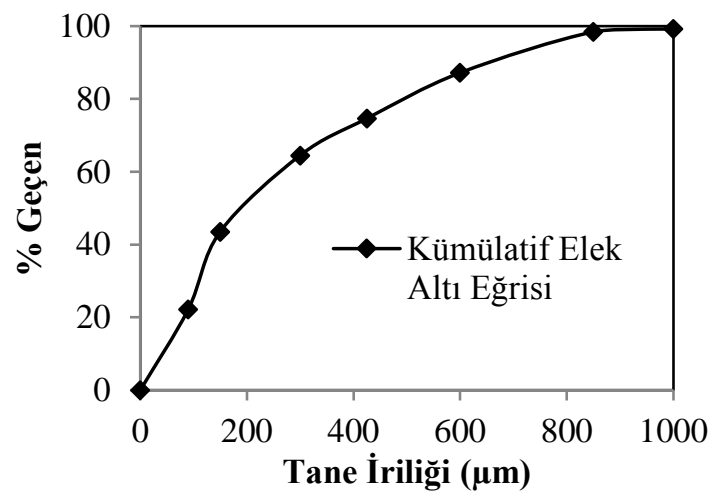

Şekil 1. Spekülarit cevherinin tane boyut dağılımı

Boyut küçültmenin ardından malzemelerin \%80'inin geçtiği tane boyutu (d80) yaklaşık $500 \mu \mathrm{m}$ 'dir. MiniPal4 PANalytical XRF cihazı ile spekülarit numunesine uygulanan analiz sonucu belirlenen kimyasal içerikler Çizelge 4'te verilmiştir. Rigaku MinFlex II XRD cihazı ile yapılan analiz sonucunda ise numunenin mineralojik içeriği belirlenmiştir (Şekil 2). Çizelge 4 ve Şekil 2'de görüldüğü gibi yüksek $\mathrm{SiO}_{2}$ içeriği $(>\% 30)$ incelenen sipekülarit cevherinin endüstriyel kullanımını engellemektedir.

Çizelge 4. Besleme malının kimyasal bileşimi

\begin{tabular}{|c|c|}
\hline Bileşen & \% \\
\hline $\mathrm{Fe}_{2} \mathrm{O}_{3}$ & 62,94 \\
\hline $\mathrm{SiO}_{2}$ & 32,70 \\
\hline $\mathrm{Al}_{2} \mathrm{O}_{3}$ & 3,50 \\
\hline $\mathrm{CaO}$ & 0,10 \\
\hline $\mathrm{V}_{2} \mathrm{O}_{5}$ & 0,03 \\
\hline $\mathrm{K}_{2} \mathrm{O}$ & 0,26 \\
\hline $\mathrm{SO}_{3}$ & 0,23 \\
\hline $\mathrm{Cr}_{2} \mathrm{O}_{3}$ & 0,03 \\
\hline $\mathrm{CuO}_{2} \mathrm{O}$ & 0,01 \\
\hline $\mathrm{Rb}_{2} \mathrm{O}$ & 0,09 \\
\hline $\mathrm{La}_{2} \mathrm{O}_{3}$ & 0,13 \\
\hline
\end{tabular}

Numunenin demir içeriğine göre yapılan elek metal analizi sonucu demir içeriğinin tane boyutu arttıkça azaldığı belirlenmiştir (Şekil 3). Spekülarit numunelere kuru ve yaş manyetik ayırma deneyleri numunesine uygulanan deneylere ait akım şeması Şekil 4'de görülmektedir. $425 \mu \mathrm{m}$ boyutu altındaki uygulanırken 425-108 $\mu \mathrm{m}$ boyutundaki malzeme lere sallantılı masa deneyleri uygulanmıştır.

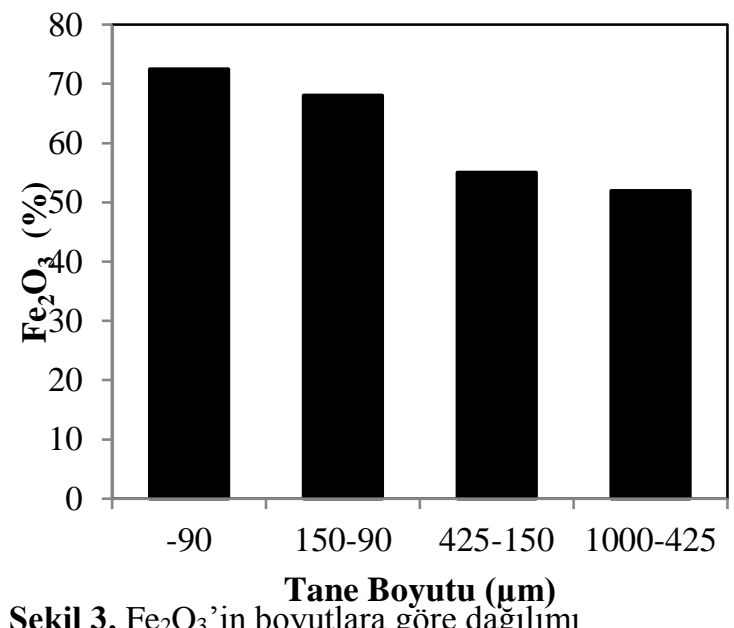

Şekil 3. $\mathrm{Fe}_{2} \mathrm{O}_{3}$ ' in boyutlara göre dağılımı 


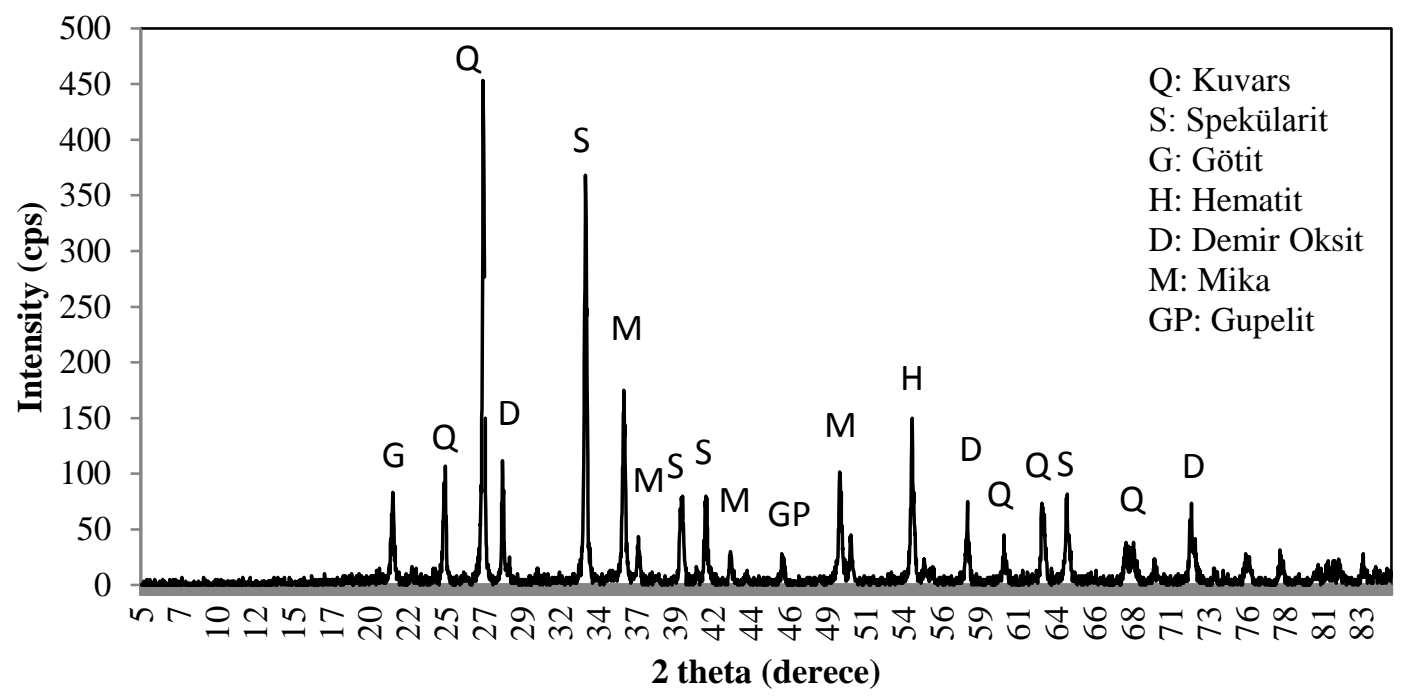

Şekil 2. Numunenin XRD diyagramı

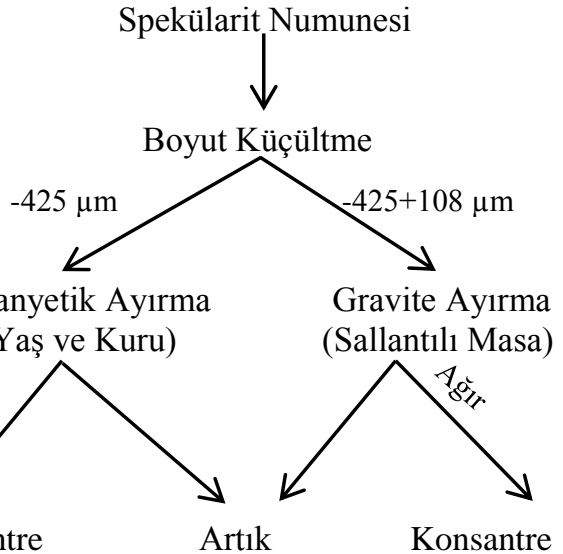

Konsantre
Artık

Şekil 4. Çalışmanın deneysel akım şeması

Yaş manyetik ayırma deneylerinde \% 20 katı oranında hazırlanan pulp $300 \mathrm{dev} / \mathrm{dk}$ hizda karıştırıldıktan 5 dakika sonra manyetik ayırıcıya beslenmiştir. Testlerde Eriez L4-20 marka laboratuvar ölçekli yüksek alan şiddetli yaş manyetik ayırıcı kullanılmıştır. Kuru manyetik ayırma deneyleri laboratuvar ölçekli Frantz marka kuru manyetik ayırıcı ile gerçekleştirilmiştir. Sallantılı masa testleri Ünal Mühendislik'e ait laboratuvar ölçekli sallantılı masa ile yapılmıştır. Sallantılı masaya yaklaşı $1 \mathrm{~kg}$ numune beslenmiş olup su sarfiyatı 10 l/dk olarak gerçekleşmiştir.

Sallantılı masa eğimi $4^{0}$ 'de çalışılmıştır. Manyetik ayırma deneylerinde manyetik alan şiddeti, sallantılı masa deneylerinde ise genlik değişken parametreler olarak belirlenmiştir.

\section{DENEYSEL BULGULAR}

4000, 6000, 8000, 10000, 12000 ve 14000 Gauss olmak üzere 6 farklı manyetik alan şiddetlerinde gerçekleștirilen manyetik ayırmalar sonucu elde edilen konsantrelerin demir tenörü değerleri ve verimleri Şekil 5'te verilmiştir.

Manyetik alan şiddetinin artmasıyla konsantrenin demir tenörleri azalmaktayken verimlerde artış gerçekleşmiştir. Manyetik alan şiddetinin artmasıyla safsızlıkların (beyaz renkteki kuvars) artış1 gözlenmişstir.

Kuru manyetik ayırıcı ile gerçekleştirilen deneylerde \%90'a varan verim elde edilmesine rağmen konsantrenin $\mathrm{Fe}_{2} \mathrm{O}_{3}$ tenörünün \%76'nın üzerine çıkmadığ belirlenmiştir (Şekil 6).

Ayrıca sallantılı masa deneylerinde genlik değerinin spekülarit cevherinin zenginleştirilmesi üzerine etkileri araştırılmıştır (Şekil 7). Testlerde manyetik ayırma testlerinden farklı olarak ara ürün de elde edilmiştir. 


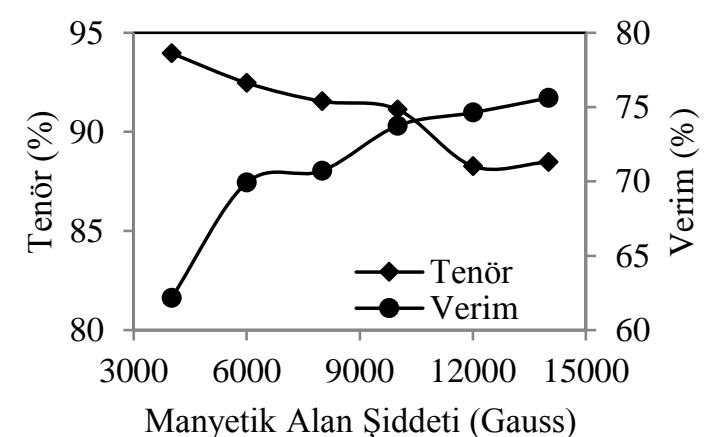

Şekil 5. Yüksek alan şiddetli yaş manyetik ayrımı tenör-verim dağılım ilişkisi

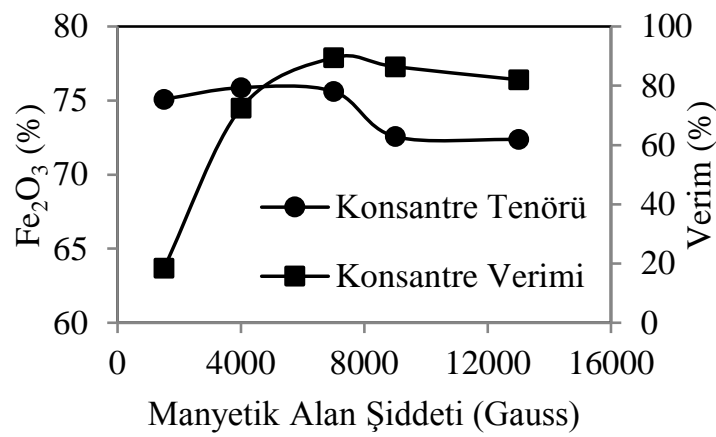

Şekil 6. Kuru manyetik ayırma sonucu elde edilen konsantrelerin tenör ve verimleri

Genlik arttıkça konsantre tenörünün azaldığı fakat miktarının arttığı söylenebilir. Konsantrelerin $\mathrm{Fe}_{2} \mathrm{O}_{3}$ tenör değerleri yüksek olmasına rağmen ara ürün de oluşması konsantre verimini düşürmüştür. Tesis bazında bir proses düşünüldüğünde ara ürünün de tekrar zenginleştirileceği öngörüldüğünden ara ürün içerikleri dağıtılmış ve konsantre verimleri Çizelge 5'de verilmiştir.

Çizelge 5. Ara ürün dağıtılmadan önceki ve sonraki verim değerleri (\%)

\begin{tabular}{|c|c|c|}
\hline Genlik (dev/dk) & Önce & Sonra \\
\hline 108 & 62,88 & 88,36 \\
\hline 126 & 61,79 & 87,20 \\
\hline 144 & 71,32 & 87,36 \\
\hline 156 & 75,91 & 90,55 \\
\hline 170 & 75,54 & 90,56 \\
\hline 240 & 75,89 & 89,07 \\
\hline
\end{tabular}

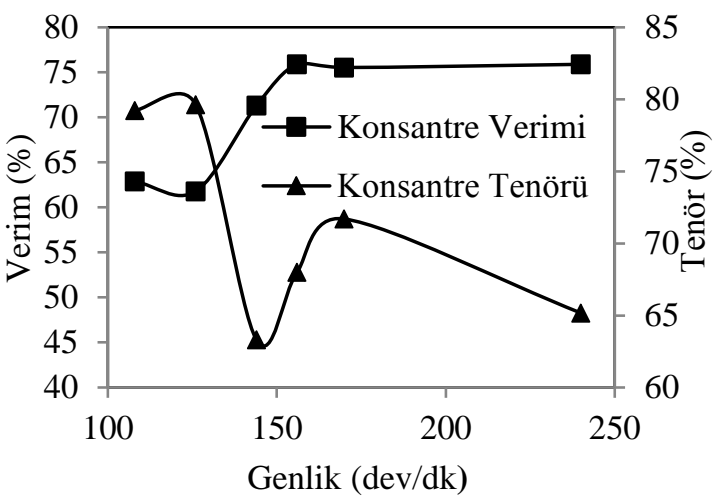

Şekil 7. Sallantılı masa konsantrelerinin verim ve tenör değerleri

6000 Gauss'luk manyetik alan şiddetinde gerçekleştirilen yaş manyetik ayırma testinden elde edilen konsantre, verim $(\% 69,91)$ ve tenör bakımından endüstriyel ölçekte kullanıma uygun niteliktedir (Şekil 8). Bu malzemenin kimyasal bileşiminde $\% 92,47 \quad$ oranında $\quad \mathrm{Fe}_{2} \mathrm{O}_{3}$ bulunmaktadir.
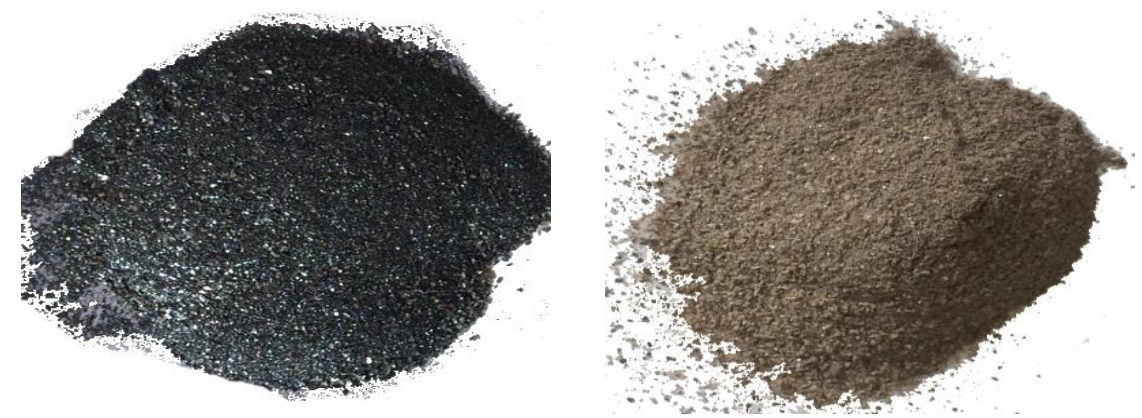

Şekil 8. 6000 Gauss'ta yaş manyetik ayırma ile elde edilen konsantre (koyu renk) ve artık (açık renk) 
Yaş manyetik ayırma işleminin kuru manyetik ayırma işleminden daha başarılı olmasının nedeni olarak yaş manyetik ayırma deneylerinde spekülarit taneciklerinin yüzeylerinde bulunabilecek safsılıkların yıkanması suretiyle daha kolay bir ayrım sağlanması gösterilebilir. Kuru manyetik ayırıcıda gang mineralleri ile spekülarit taneciklerinin birlikte salkımlaşması daha yüksek tenörde malzeme kazanımını engellemiştir.

Konsantre tenörleri ve kazanma verimleri incelendiğinde spekülarit cevherinin zenginleştirilmesi için artandan azalana göre yaş manyetik ayırma, kuru manyetik ayırma ve sallantılı masa (yoğunluk farkına göre) ile ayırmanın tercih edilebileceği saptanmıştır.

\section{SONUÇLAR}

Bu çalışmada spekülarit cevherinin fiziksel yöntemlerle zenginleştirilmesi araştırılmıştır. $\mathrm{Bu}$ amaçla yaş/kuru manyetik ayırma ve masa ile gravite ayırma deneyleri uygulanmıştır. Yapılan testler ışı̆̆ında aşağıdaki çıkarımlarda bulunulmuştur:

- Çalışma kapsamında demir-çelik tesislerinde doğrudan şarj malzemesi olarak kullanılabilecek $\mathrm{Fe}_{2} \mathrm{O}_{3}$ tenörüne $(>\% 91,5)$ ve safsızlık değerlerine sahip spekülarit konsantresi yaş manyetik ayırma ile elde edilmiştir.

- Doğal demir oksit pigmenti olarak kullanılabilecek tenörlerde spekülarit konsantresi (mikalı demir oksit için $>\% 85$ $\mathrm{Fe}_{2} \mathrm{O}_{3}$ ) elde edilmiştir.

- Yüksek alan şiddetli yaş manyetik ayırma deneylerinde 4000 Gauss'ta \%93,97 $\quad \mathrm{Fe}_{2} \mathrm{O}_{3}$ tenörlü konsantre \%62,14 kazanma verimiyle elde edilmiştir. Aynı yöntem ile 6000 Gauss'ta $\% 92,47 \quad \mathrm{Fe}_{2} \mathrm{O}_{3}$ tenörlü konsantre \%69,91 verimle elde edilmiştir. Daha yüksek manyetik alan şiddetlerinde $\mathrm{Fe}_{2} \mathrm{O}_{3}$ tenörü azalmıştır.

- Kuru manyetik ayırma testlerinde \%75,62 $\mathrm{Fe}_{2} \mathrm{O}_{3}$ içeren konsantre \%89,43 verimle kazanılmıştır.
- Sallantılı masa testlerinde \% 71,7 $\mathrm{Fe}_{2} \mathrm{O}_{3}$ içerikli konsantre \%75,54 kazanma verimiyle 170 dev/dk genlik değerinde elde edilmiştir.

\section{KAYNAKLAR}

1. Demir Cevheri ve Teşekkülü, Madencilik, sayı 09/6, 1970.

2. Ata, E., 2005. Divriği-Pınargözü (Sivas), Hekimhan (Malatya) ve Feke (Adana) Demir Cevherleşmelerindeki Hematitlerin Karşılaştırmalı Jeokimyasal İncelenmesi, Yüksek Lisans Tezi, Çukurova Üniversitesi, Adana

3. Çiçek, T., Çilingir, Y., 2006. Demir Cevherleri ve Zenginleştirme Yöntemleri, (DOI: 10.13140/2.1.5033.5524).

4. T.C. Kalkınma Bakanlığı, Onuncu Kalkınma Planı, Demir-Çelik Çalışma Grubu Raporu, Ankara, 2014.

5. TMMOB, Maden Mühendisleri Odası, Demir Raporu, 2009.

6. TÇÜD, Türkiye Çelik Üreticileri Deneği, Ocak Ayı Bülteni, (http://www.dcud.org.tr/tr/news.asp?news_id= 465), (Erişim tarihi : 10.08.2015), 2014.

7. Potter, M.J., 2004. Iron Oxide Pigments. In: United States Geological Survey. Compiler. Minerals Yearbook: Volume 1-Metals and minerals. United States Department of the Interior.

8. http://www.boyaturk.com/Haber/TozRenklendirici-Demir-Oksitler.html, (Erişim tarihi: 10.05.2015), 2015.

9. Harben P.W., 1999. The Industrial Minerals Handybook, 3rd Edition. Industrial Minerals Information Ltd, London.

10. Burghardt, O., $1979 . \quad$ Die Qualitaetsverbesserung von Eisenerzprodukten Durch Neue Aufbereitungsverfahren, Glückauf Heft 11.

11. Xiuping, G., Wenxin, Q., Zhiqiang, Z., 2004. Experimental Research on Reverse Flotation of an Intergrown Specularite Ore, Metal Mine, 02 .

12. W. Z. Wang, J. R. Zhang, C. G. 2011. Yang, Experimental Research on Beneficiation 
Process for a Specularite Ore, Advanced Materials Research, Vol. 304, 387-390, Jul.

13. Wei-guo, C., 2011. Research on Mineral Processing Technique of a Specularite Ore from Xinjiang, Mining and Metallurgical Engineering,.

14. Naude, N., Lorenzen, L., Kolesnikov, A.V., Aldrich, C., Auret, L., 2013. Observations on the Separation of Iron Ore in a Prototype Batch Jig, International Journal of Mineral Processing, 120, 43-47.

15. Ezhov, A.M., Shvaljov, Y.B., 2015. Dry Magnetic Separation of Iron Ore of the Bakchar Deposit, Procedia Chemistry, 15, 160166 ,

16. Oshitani, J., Kajimoto, S., Yoshida, M., Franks, G.V., Kubo, Y., Nakatsukasa, S., 2013. Continuous Float-Sink Density Separation of Lump Iron Ore Using a Dry Sand Fluidized Bed Dense Medium. Advanced Powder Technology, 24, 468-472,

17. Kumar, D.R., Srinivas, R.D., Ram, R.P.S., 2013. Magnetic Separation Studies for a Low Grade Siliceous Iron Ore Sample, International Journal of Mining Science and Technology, 23, $1-5$. 